\title{
Research on the Learning Behavior of University Students in Blended Teaching
}

\author{
Jiangbo Shu, Qianqian Hu, and Min Zhi
}

\begin{abstract}
Learning analysis is the motive force of optimizing teaching and realizing individualized learning. Compared with the study of learning behavior in the network environment, it was relatively less in the mixed teaching mode. In this paper, students' attention performance in class and resource learning performance online were taken as the research object to explore the characteristics of students' learning behavior in mixed teaching mode. First of all, the attention data acquisition model was used to collect the students' performance data in class to explore the attention performance characteristics of students. Secondly, the effective time length calculation model was used to filtrate effective online learning records. Finally, based on the above research, the correlation was explored between students' online learning behavior and offline learning behavior, and the learning performance between current course and other courses. Research showed that those who came from different faculties and majors but taking the same optional course , their online learning behavior performance had a significant positive correlation with their classroom learning behavior. In addition, their learning behavior performance in the current course had significant positive correlation with grades of the similar course in the past. It indicates that the students' learning behavior is relatively stable under the blended teaching pattern in Colleges and universities.
\end{abstract}

Index Terms-Blended teaching pattern, learning behavior analysis, correlation analysis.

\section{INTRODUCTION}

In recent years, with the development of educational informationization, The study of blended teaching pattern, intelligent classroom and educational big data has gradually entered into the application stage. The exploration and practice of mixed teaching mode accelerate the transformation of education mode and study mode, it's the key to make educational reform keeping pace of the change of age [1]. The construction and application of the intelligent classroom make the physical classroom and the network classroom seamless integration, and realize the integration of the physical space and the virtual space. It is the inherent requirement of the development of school information to a certain stage, and it is also the inevitable choice of the age of

Manuscript received January 24, 2018; revised August 12, 2018. This research was partially funded by the National Key Research and Development Program of China (No.2017YFB1401303), the Fundamental Research Funds for the Central Universities (No.CCNU17TS0002), the National Natural Science Foundation of China under Grant (No.61505064, No.61702211), the Project of the Program for National Key Technology Research and Development Program (2014BAH22F01).

The authors are with National Engineering Research Center for e-Learning, Central China Normal University, Wuhan, Hubei 430079 China (e-mail: shujiangbo@mail.ccnu.edu.cn, 972455086@qq.com, 2311230078@qq.com). intelligent learning [2]. The research of educational big data application attempts to break through the key technologies of data acquisition, modeling, analysis and visualization, and build educational big data aggregation and service platform, promoting the development of education become more accurate, personality and intelligence. Blended teaching pattern, intelligent classroom and educational big data provide strong support for the development of learning analysis technology, promoting the education informationization reform from three aspects: Transformation of teaching mode, updating of teaching environment, and support of data services.

\section{RELATED RESEARCH}

As an important part of learning analysis, the analysis of learning behavior has become a hot topic for scholars. The analysis of learning behavior refers to the objective analysis of the related behavioral data recorded in the learning process [3].

At present, according to the different teaching environment, the domestic learning behavior analysis can be divided into two categories: one is the learning behavior analysis under the network teaching environment, the other is the learning behavior analysis under the mixed teaching environment.

$\mathrm{S}$. Li explored the online participation mode of learners by dividing them into five types according to their online behavior sequence characteristics and concluded five kind of online participation modes [4]. G. Mao built an analysis model of problem learning behavior in web-based learning environment, aiming to explore behaviors and patterns that are beneficial to learning effect, and provide decision support for discovering, analyzing and intervening problem learning behaviors in time [5]. H. Luo collected and analyzed the website traffic data for six years in the open course, and revealed the general characteristics and evolution trend of learner community and learning behavior in open courses [6]. G. Fu used data mining method and statistics method to conduct the quantitative analysis of web learners' behavior characteristics, and discussed the relationship between network learning behavior characteristics and learning effect [7].

The main purpose of blended learning (B-learning) is to help students get the best learning effect [8]. Z. Liu analyzed the forum data generated in the online learning platform of college students, proving that there is a positive correlation between learners' interaction and their learning performance in the forum [9]. Subsequently, they analyzed the online learning behavior records of freshmen in one year, and explored the differences of online learning behaviors 
characters among different grades under mixed education pattern in the university environment [10]. The research mentioned above mainly explores the relationship between online learning behavior patterns and rules and their learning achievements in a mixed teaching environment. Based on the learning performance of 39 postgraduate two graders in two courses, H. Wang encoded their classroom learning behavior, online learning behavior and cognitive behavior to explored the behavioral differences between deep and shallow learners from the perspective of cognition [11]. Based on the accumulated learning data of students in the same course, Y. Yang adopts correlation analysis method to explore the relationship between learning behavior and learning effect from three aspects, namely, traditional classroom teaching records, network platform behavior data and APP browsing records of mobile terminals [12]. The above research was based on online and offline integrated learning behavior analysis, recording learners' learning behavior, mining learners' learning habits, analyzing learners' learning styles, and exploring the relationship between learning behavior and learning outcomes.

In this paper, students' attention performance in class and resource learning performance online were taken as the research object to explore the characteristics of students' learning behavior in mixed teaching mode.

\section{RESEARCH DESIGN}

\section{A. Research Environment}

In order to promote the reforming process of teaching methods and teaching modes under the environment of the educational informatization, improve students' ability of autonomous learning and cultivate their ability of discovering, analyzing and solving problems, Center China Normal University (CCNU) started the project of reforming blended teaching pattern in 2013. By 2017, Cloud integrated teaching platform, which could also be called starC_spoc, has been designed and developed by CCNU. The platform has been applied the technology of cloud computing, large data and so on and taken the teaching, learning and management of the curriculum as the core element. According to the modern education theory, the platform realized the effective connection between the five spaces, including campus space, department space, teacher space, student space and curriculum space, by combining the campus physics classroom with the cloud virtual classroom.

In the process of the application of the blended teaching pattern, a large number of behavior recording of classroom teaching and online learning are gathered by the platform of starC_spoc. In this paper, the classroom video, online learning behavior records, and courses' grade in the past semesters have been extracted as research datasets.

\section{B. Research Problem}

The purpose of this study is to analyze and summarize students' learning behavior under the blended teaching pattern in Colleges and universities, and to explore the correlation between individual online and offline learning behaviors and the correlation with past semester's academic performance.
Based on the purpose of this study, the following 4 research questions are proposed.

1) What are the characteristics of the students' attention performance in the class? Is the student's individual performance consistent in different lessons?

2) Is students' resource learning progress of each chapter matched with the classroom teaching schedule in the online learning environment with sufficient learning resources? would student cram for the examination at the end of the semester?

3) Is the student's attention performance related to the performance of the resource learning? Are good students perform well both in online learning and offline learning?

4) Is there a relative stability of the students' learning performance? Are excellent students performing well both in current and other courses?

\section{Research Object}

In the first semester of the academic year 2017-2018, there were 82 undergraduate classes being started teaching both in a smart classroom (off-line) and in the cloud classroom (online). the course of "Network Entrepreneurship Theory and practice" was chosed as the target class finally, which had a high degree of curriculum construction and better students' learning performance. According to the contents of the course chapters, the online resources were divided into different parts. Each part included coursewares and micro-lectures, maybe 10 to 20 minutes, and also a variety of expansion resources. In addition, the teachers incorporated the students' online learning performance into the assessment index, and the recommended learning time for each section was 120 minutes. From the 80 person's classroom, according to the seat distribution of students, 8 students who sat in different areas were randomly selected as target students, coding S1-S8 respectively.

\section{Data Sources}

The data in this study consisted of three parts, one was the attention data of the 8 target students, mainly from the classroom video. The second was the online resource learning performance of the 8 target students. Students learning in cloud classroom would produce a lot of learning behavior log data. By collecting and cleaning up their behavior logs, the learning time data of 8 target students was considered as online learning datasets. The third was the achievements of the 8 students in the past semester, which were mainly derived from the school educational administration system.

\section{RESEARCH METHODS}

This part gives a detailed description of the basic methods for the analysis of students' behavior under the mixed teaching model. First, select the continuous classroom performance behavior records and online learning behavior records of target students and groups, and use correlation analysis algorithm to do correlation analysis. For this purpose, classroom learning performance is mainly measured by the attention capacity, and online learning behavior is mainly measured by the length of the learning time of the curriculum 
resources. Second, classroom records can not be used directly for calculation, it need to be preprocessed and extracted effective attention data from it. In fact, online learning behavior records may have invalid behavior records, and need to be screened to filter out effective learning behavior records.

\section{A. The Students' Attention Data Collection}

Take the students' attention data collection of one lesson as example, the concrete steps are as follows: Input:

1) A photo set of all members of the class $A:\left\{<S_{i}, G_{i}>\right\}$, i represents student's number, $S_{i}$ represents student I, $G_{i}$ stands for the photo of $S_{i}$.

2) $\mathrm{B}$, the cutting map of classroom seat. Different classrooms have different seating layout. In one section of the class, the seats chosen by students are relatively fixed. According to the video taken by the camera in the selected classroom, the seating map is drawn as shown in Fig. 1.

3) The classroom video $\mathrm{V}$ of $\operatorname{section} C_{j}$, using $T_{k}$ as the time series, in which $\mathrm{k}$ is the sequence number of the time series and numbered from the beginning of the section $\mathrm{j}$ of the course.

Output:

The attention dataset $\mathrm{F}:\left\{\left\langle S_{i}, C_{j}, T_{k}, U\right\rangle\right\}$, where each record represents the attention performance $U$ of students $S_{i}$ at the time $T_{k}$ of section $C_{j}$ ( As for data $\mathrm{U}$, number 1 stands for looking up, number 0 represents looking down, and number -1 represents Null).

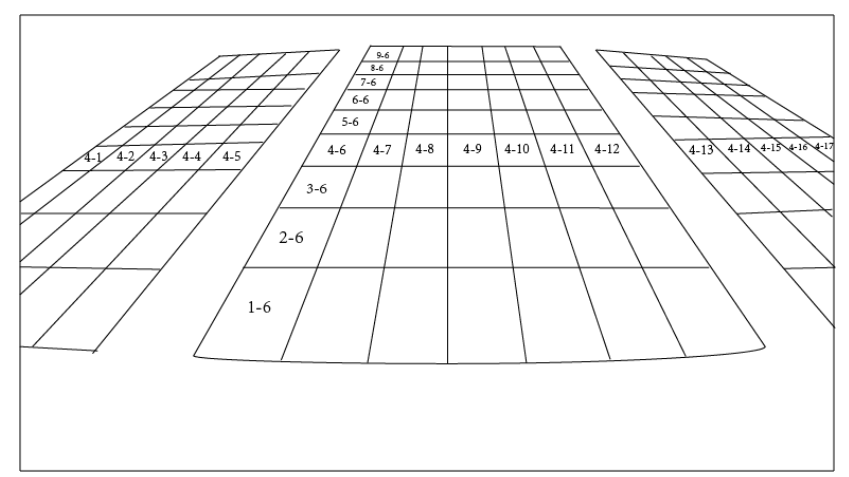

Fig. 1. Cutting map of classroom seat.

Process:

Step1: Video decomposition. With 10s as the interval, the classroom video $\mathrm{V}$ need to be transformed into image sequence, which would be stored into set I, $I=\left\{j \in Z, 0<=j<N_{v} \mid m_{\mathrm{j}}\right\} . N_{v}$ stands for the total number of images converted by the video $\mathrm{V} ; m_{\mathrm{j}}$ represents the captured picture at time $\mathrm{j}$. The time sequence of the images collection would be stored into set $\mathrm{T}, T=\left\{j \in Z, 0<=j<N_{v} \mid T_{\mathrm{j}}\right\}$, in which $T_{\mathrm{j}}$ represents the acquisition time of the picture $j$.

Step 2: Image segmentation. the image segmentation of each picture $m_{\mathrm{j}}\left(0<=j<N_{v}\right)$ in the image sequence set $\mathrm{I}$ is implemented according to the cutting map of classroom seat, being stored in $M_{\mathrm{j}}=\left\{k \in Z, 0<k<N_{p} \mid<P_{k}, G_{k}>\right\}$, $N_{p}$ is the total number of seats in the classroom, $P_{k}$ stands for the location number of the seat k, and the $G_{k}$ 'represents the corresponding picture of $P_{k}$.

Step 3: individual student identification.Copy the set A to the collection A', compare each student's picture in the collection $\mathrm{A}^{\prime}$ with the image of $M_{\mathrm{j}}$ one by one. If the match is successful, getting the relationship $\left.<S_{i}, P_{k}\right\rangle$ between the student $S_{i}$ and the seat number $P_{k}$, and put it into the collection $Q$, remove the picture of $S_{i}$ in set $\mathrm{A}^{\prime}$, until set $\mathrm{A}^{\prime}$ is empty or $M_{\mathrm{j}}$ has completed the comparison. Finally, a set of correspondence between the students and the seats is obtained and storded in $\operatorname{set} Q:\left\{<S_{\mathrm{i}}, P_{k}>\right\}$.

Step 4: Attention recognition. Combining the students' location information $\mathrm{Q}$ and the time information $T$, set $\mathrm{F}:\left\{\left\langle S_{i}, C_{j}, T_{k}, U\right\rangle\right\}$ can be obtained through the attention analysis of image set $M_{\mathrm{j}}$, representing all student's attention data set in section $C_{j}$.

In the above processing, some third party interface are used, such as face recognition technology and expression recognition technology, and the algorithm would not to be explained in detail.

\section{B. The Weighted Attention Calculation}

The analysis of students' individual attention needs to be based on the performance of all students in the class. For example, teachers' questions can prompt most of the students to show positive attention performance in a certain time, while in the thinking stage, the whole attention performance of students can be relatively negative. In order to make the students' attention data more accurate, the attention weighted model is proposed in this paper.

Input:

The attention dataset $\mathrm{F}:\left\{\left\langle S_{i}, C_{j}, T_{k}, U\right\rangle\right\}$, where each data represents the attention data of students $S_{i}$ at the time $T_{k}$ of class $C_{j}$ is $\mathrm{U}$ ( number 1 stands for looking up, number 0 represents looking down, and number -1 represents Null).

Output:

The weighted attention dataset $F_{+}:\left\{\left\langle S_{i}, C_{j}, T_{k}, U_{+}\right\rangle\right\}$, where each data represents the attention data of students $S_{i}$ at the time $T_{k}$ of class $C_{j}$ is $U_{+}$.

Process:

Step1: Calculate the class overall attention dataset $R:\left\{<C_{j}, T_{k}, R_{j k}>\right\}$, where each record indicates the overall attention of the students at the time $T_{k}$ of the lesson $C_{j}$ is $R_{j k}$.First, sum up the attention data of all the students at the time $T_{k}$ of the lesson $C_{j}$, then divide it by the total 
number of students in the lesson $C_{j}$, and get the class overall attention at different times.

The calculation formula is

$$
R_{j k}=\frac{\sum_{i=1}^{n} U_{i j k}}{n}
$$

$n$ is the total number of students in lesson $C_{j}$.

Step2: It is assumed that the weighted attention model is as follows:

$$
\theta=\left\{\begin{array}{rr}
1, & 75 \%<R_{j k} \leq 100 \% \\
2, & 50 \%<R_{j k} \leq 75 \% \\
3, & 25 \%<R_{j k} \leq 50 \% \\
4, & 0<R_{j k} \leq 25 \%
\end{array}\right.
$$

The the weighted attention dataset $O:\left\{<C_{j}, T_{k}, \theta>\right\}$ is obtained by calculation, in which each record represents the value of the weighted attention at the time $T_{k}$ of the lesson $C_{j}$.

Step3: Calculated the weighted attention performance of students. The calculation formula is

$$
F_{+}=f(F, O)
$$

The calculation method can be described as: $<S_{i}, C_{j}, T_{k}, U>\oplus<C_{j}, T_{k}, \theta>=<S_{i}, C_{j}, T_{k}, U_{+}>$

For every lesson $C_{j}$ at evary moments $T_{k}$, the following formula is used to deal with the attention value $\mathrm{U}$ in the set $\mathrm{F}$ and the weighted attention value $\theta$ at the corresponding time in the set $O$.

$$
U_{+}=\left\{\begin{array}{ll}
U, & U<1 \\
\theta, & U=1
\end{array},\right.
$$

The weighted attention dataset of students was finally obtained as $F_{+}:\left\{\left\langle S_{i}, C_{j}, T_{k}, U_{+}\right\rangle\right\}$.

\section{The Effective Learning Time Calculation}

In this paper, the teachers incorporated the students' online learning performance into the assessment index, and the recommended learning time for each section was 120 minutes. But there is some data more than the length of the recommended learning time in some students' learning behavior data. After analysis, these learning records are produced by the students' abnormal learning behavior, which does not belong to the scope of effective learning. In order to eliminate these data, the effective time formula is defined. For each teaching resource, the student's original learning duration is accumulated as $T n$, and the recommended learning time is recorded as $M_{t}$, then the effective learning time can be calculated as follows:

$$
T n^{\prime}=\left\{\begin{array}{lr}
0, & M_{t}<T n \\
T n, & 0<T n \leq M_{t}
\end{array}\right.
$$

\section{RESULTS AND ANALYSIS}

\section{A. The Analysis of Students' Attention Performance in Class}

In order to explore the characteristics of College Students' attention capacity in class, it will be given detailed analysis from three aspects: personal attention capacity, students' overall attention performance and the wighted attention of each student. First, from the perspective of individual students, the same students' attention performance in different lessons would be compared and analyzed.Secondly, from the perspective of each lesson, the whole class attention performance of different students would be analyzed.Thirdly, the weighted attention of different students would be quantified and analyzed.

1) the Analysis of Personal Attention Performance in Class

Through the statistical analysis of the collected attention data of students in class, and using the simple linear regression based on least square method, the fitting line of attention capacity of different students could be drawn as follows. Taking student S8 as example, as shown in Fig. 2, the $\mathrm{X}$ axis in the graph represented the time series, The $\mathrm{Y}$ axis represented the total number for looking up to the blackboard and listening. The 10 thinner lines in the picture stood for the attention capacity of the student S8 from the forth week to the fourteenth week (the sixth week was the holiday week). The thicker line was the fitting line of all class attention of the student S8. In this mode, the attention performance of each student is shown as shown in Fig. 3. Eight small pictures on the right side of the picture show the class attention of eight students, respectively. The left side of the picture was the attention capacity of different students, using the fitting line in different color to represent different student.

As shown in Fig. 3, the attention performance of student S1, S4, S6, S7, and S8 were relatively stable in class. All students, except for student S8, showed relatively negative performance in class. Students S2, S3 and S5 was relatively positive in class, but the attention performance was fluctuated in general.

Therefore, students, whose classroom performance were relatively negative, their performance relatively stable in each lesson of the course, no major fluctuations. In this way teacher could quickly identify these students after class, and give the appropriate teaching intervention. While the students with better performance in the classroom, their performance fluctuated relatively greatly in general.

2) the Analysis of Students' Overall Attention Performance

The analysis of students' individual attention needs to be based on the performance of all students in the class. Through the statistical analysis, the fitting line of attention capacity of students in each lesson could be drawn as Fig. 4. The overall attention of the students was relatively positive in the eleventh week, and was relatively negative during the ninth and 
fourteenth week. After viewing the teaching videos, it had been found that in the eleventh week, the teacher hired the head of the start-up company outside school to share their entrepreneurial experience. It can be seen that introducing activities that students interested in can improve students' overall attention, and students' classroom performance is greatly influenced by teachers' teaching strategies.

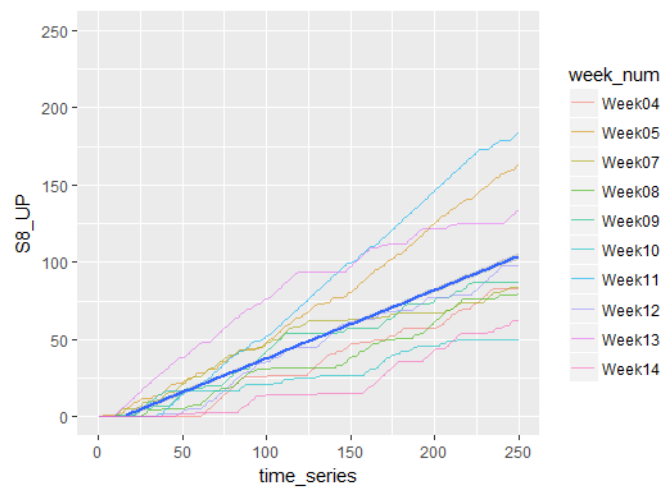

Fig. 2. Attention performance of student S8 in class.

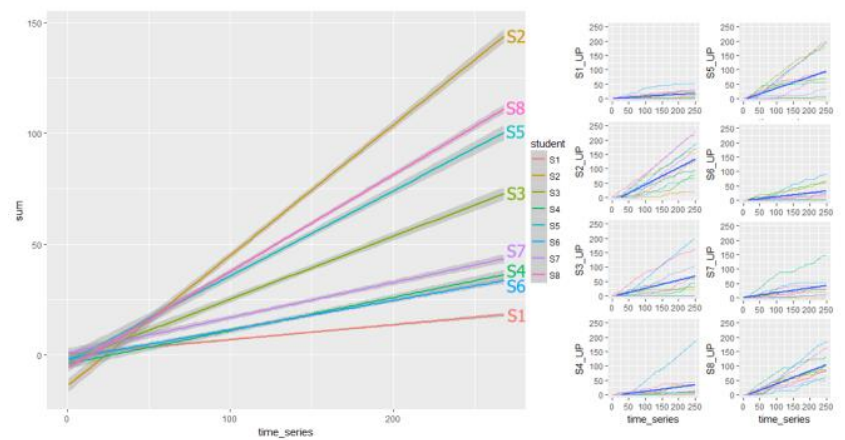

Fig. 3. Attention performance of each student in class.
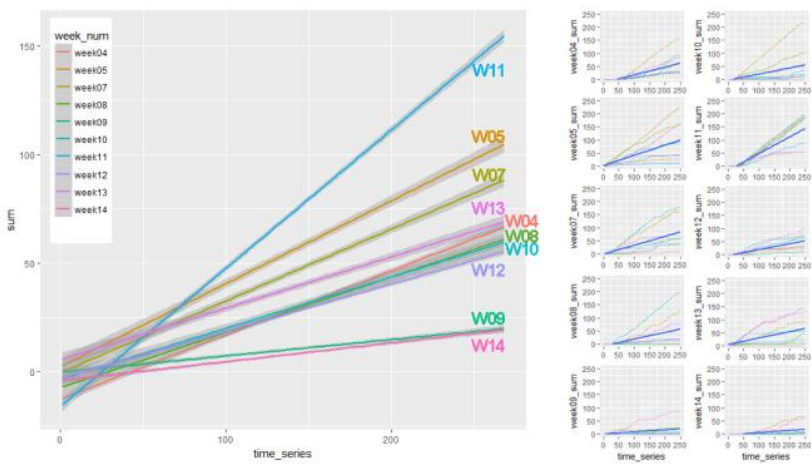

Fig. 4. Students' overall attention performance in each lesson.

3) the Analysis of the Weigted Attention of Students in Class

After obtaining the weighted attention data of students, the total number of the weighted attention of each student could be calculated and drown as Fig. 5. The $X$ axis in the figure represented the number of student, and the $\mathrm{Y}$ axis stood for the weighted attention value. Compared with the attention performance of each student, the performance of the weighted attention of each one was basically coincident.

In summary, with the weakening of the influence of group factors on students' attention, there was no significant fluctuation in the relative ranking of students' attention performance, which could faithfully reflect students' classroom performance. The weighted attention data, as the overall representative of the students' class performance, can provide data support for the related analysis of online resource learning.

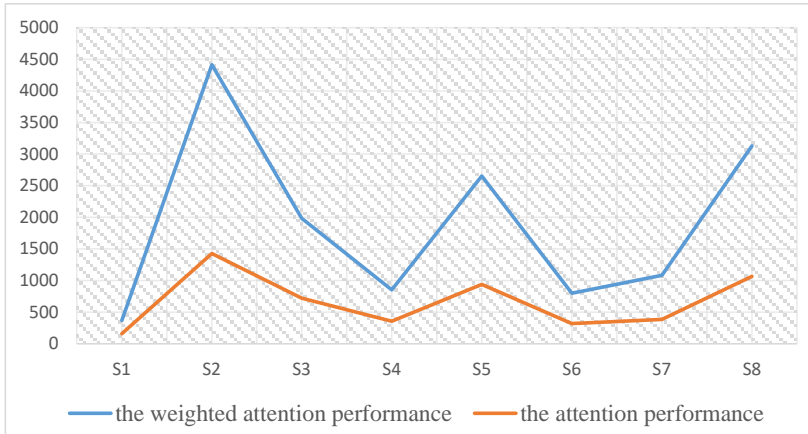

Fig. 5. The weigted attention of students in class.

\section{B. The Analysis of Learning Performance of Students out of Class}

The students' learning in different chapters could reflect the students' learning attitude more carefully. As shown in Fig. 6, the $\mathrm{X}$ axis represented the chapter resource number; the $\mathrm{Y}$ axis represented different students. In Fig. 7, student S2, ranking first in the learning time, the learning time of some chapter resources was far beyond the valid time range. S8, S2 and S6 had more average and effective learning time in different chapters. S4, S1, S7 and S3 not only had less time for learning, but lower utilization of resources.

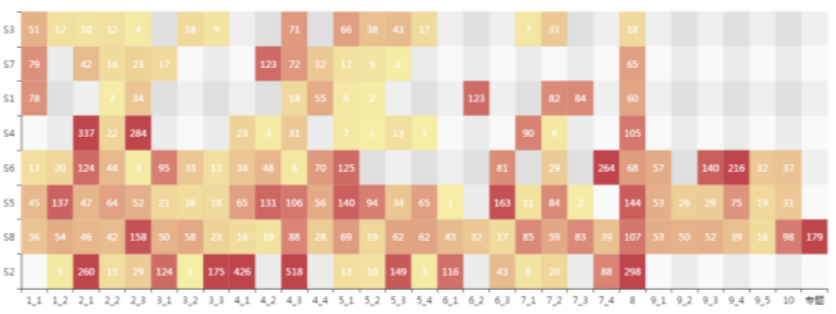

Fig. 6. Students' resource learning performance in different chapters.

\section{The Analysis of Learning Performance of Students Both in Class And out of Class}

In order to analyze the students' learning performance comprehensively, the weighted attention in class and the effective resource learning time out of class were counted by week as in Fig. 7. In each group of histogram, the left was the weighted attention of all weeks, and the right was the effective resources learning time.

It could be seen that students with better attention in class were more excellent in learning resources. However, there was no significant relationship between the attention and the resource learning.

\section{The Analysis of Learning Performance of Students in Current Course and in Other Courses}

As the public elective course selected by this paper, students came from different faculties and different specialties. From the students' achievements in past semesters, the grades of the courses that all students had already learned were selected firstly, then the Pearson related analysis was carried out among the achievements of selected courses, the weighted attention in class and the effective learning time of 
the resources out of the class.

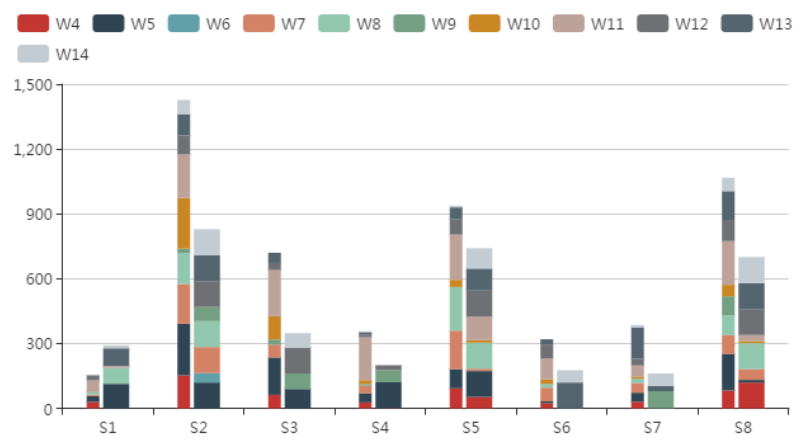

Fig. 7. The learning performance of students in class and out of class.

From Table I, the conclusion could be drawn that the learning performance of 8 students in class and out of class, and the achievements of other courses in past semesters were significantly correlated with each other.

Research showed that those who came from different faculties and majors but taking the same optional course , their online learning behavior performance had a significant positive correlation with their classroom learning behavior. In addition, their learning behavior performance in the current course has significant positive correlation with grades of the similar course in the past semesters. It indicates that the students' learning behavior is relatively stable under the blended teaching pattern in Colleges and universities.

TABLE I: The LEARNING PERFORMANCE OF STUDENTS IN CURRENT COURSE AND IN OTHER COURSES

\begin{tabular}{|c|c|c|c|c|}
\hline & & A & $\mathrm{B}$ & $\mathrm{C}$ \\
\hline \multirow{3}{*}{$\begin{array}{l}\text { A (the Weighted } \\
\text { Attention in } \\
\text { Class) }\end{array}$} & Pearson Related & 1 & $.919^{* * *}$ & $.872^{* * *}$ \\
\hline & Saliency (two-tailed) & & 0.001 & 0.005 \\
\hline & $\mathrm{N}$ & 8 & 8 & 8 \\
\hline \multirow{3}{*}{$\begin{array}{l}\text { B (the Effective } \\
\text { Learning Time of } \\
\text { Resources) }\end{array}$} & Pearson Related & $.919^{* *}$ & 1 & $.858^{* *}$ \\
\hline & Saliency (two-tailed) & 0.001 & & 0.006 \\
\hline & $\mathrm{N}$ & 8 & 8 & 8 \\
\hline \multirow{3}{*}{$\begin{array}{l}\text { C (the } \\
\text { Achievements of } \\
\text { Selected Courses) }\end{array}$} & Pearson Related & $.872^{* *}$ & $.858^{* *}$ & 1 \\
\hline & Saliency (two-tailed) & 0.005 & 0.006 & \\
\hline & $\mathrm{N}$ & 8 & 8 & 8 \\
\hline
\end{tabular}

**. The correlation was significant at the 0.01 level (two-tailed).

\section{CONCLUSION AND SUGGESTIONS}

Explore the characteristics of students' learning behavior in mixed teaching mode,the key step is to quantify the students' learning performance in class and out of class. In this paper, students' attention performance in class and resource learning performance online were taken as the research object, and with the above analysis, the characteristics of students' learning behavior in mixed teaching mode could be concluded as follows.

1) In terms of the learning performance of students in class, it can be concluded that, as for students, the less attention focused in class, the stabler performance in each lesson, the easier finding these students through this method, and the less influence on these students with the change of teacher's teaching strategy.

2) In terms of the learning performance of students out of class, the students' learning in different chapters can reflect the students' learning attitude more carefully. The students who learn online resources more averagely and effectively in different chapters, their attitude of study is more serious.

3) In terms of the learning performance of students in class and out of class, students with better attention in class are more excellent in learning resources out of class.

4) In terms of the learning performance of students in the course and in other courses, their learning performance in the current course has a significant positive correlation with the grades of other courses in past semesters.

With the development of technology, more and more students' learning behavior has been recorded, which provides data support for educational researchers. It is likely difficult to reveal the internal causes of some phenomena by analyzing the behavior of each dimension in isolation. In order to have a better understanding of students' learning, it need to be done more related analysis of behaviors, such as discussion and answer questions in class, homework submission and so on. In the follow-up research, a more comprehensive and in-depth analysis of students' learning is particularly important, finding out the problems in the teaching and making teachers adjust the teaching strategies in time.

\section{REFERENCES}

[1] L. Chen, "Research on the construction of three-dimensional learning resources in college curriculum - The perspective of promoting the change of learning style," China Educational Technology, 2013, no. 11, pp. 95-97.

[2] R. Huang, Y. Yang, G. Xiao et al., "The functions of smart classroom in smart learning age," Open Education Research, 2012, no. 02, pp. 22-27.

[3] X. Yang, H. Wang, and J. Li, "The application of lag sequential analysis method in analyzing learning behavior," China Educational Technology, 2016, no. 02, pp. 17-23+32.

[4] S. Li, Y. Zhong, Y. Shen et al., "Exploring the online learning participation behavior pattern based on behavioral sequence analysis," China Educational Technology, 2017, no. 03, pp. 88-95.

[5] G. Mao, Q. Liu, H. Li et al., "Research and application of problem learning behavior analysis model in online learning environment," E-Education Research, 2016, no. 11, pp. 32-37+84.

[6] H, Luo, T Liu, Eliza Richardson, and M. Zuo, "Analysis of learning behaviors in an open course: Evidence from Google analytics," China Educational Technology, 2017, no. 10, pp. 8-14+31.

[7] G. Fu and G. Wang, "Research on network learning behavior and learning effect based on data mining," E-Education Research, 2014, no. 09, pp. 53-57.

[8] Q. Zhang and A. Wang, "The design of new blended learning model based on flipped classroom," Modern Educational Technology, 2014, no. 04 , pp. 27-32.

[9] Z. Liu, W. Zhang, J. Sun et al., "Analysis of learners' interactive discourse behaviors in the cloud classroom forum," E-Education Research, 2016, no. 09, pp. 95-102.

[10] Z. Liu, Y. Wang, N. Zheng et al., "Exploration of "Internet +" vocational skills cultivating and training modes," China Educational Technology, 2017, no. 07, pp. 88-94+106.

[11] H. Wang, J. Li, and X. Yang, "Research on differences of learning behaviors between deep learners and surface learners in blend learning in higher education," E-Education Research, 2017, no. 12, pp. 44-50.

[12] Y. Yang, "A comparison of collaborative learning outcomes in the blended learning setting: A social network analysis," Distance Education in China, 2016, no. 11, pp. 22-27+79-80. 


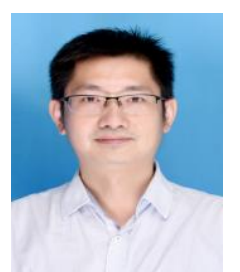

Jiangbo Shu(M' 82) received the B.S. degree in computer science and technology from Central China Normal University, Wuhan, Hubei, China, in 2005 and the M.S. degree in computer software and theory from Central China Normal University, Wuhan, Hubei, China, in 2008 and the doctorate in Chinese information processing from Central China Normal University, Wuhan, Hubei, China, in 2011.From 2011 to 2017, he is an associate professor, and working at the National Engineering Research Center for e-Learning, Wuhan, Hubei, China. His research interests include software engineering, computer application technology, cloud computing and big data.

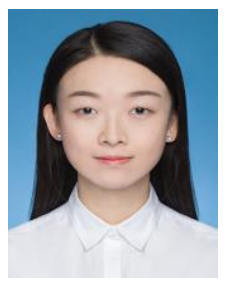

Qianqian $\mathbf{H u}$ is a master student studying at the National Engineering Research Center for e-Learning, Wuhan, Hubei, China. Her research interests include educational technology and learning analytics.

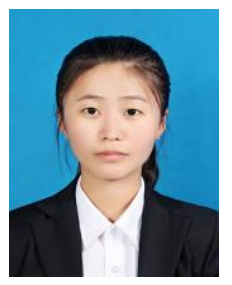

Min Zhi is a master student studying at the Nationa Engineering Research Center for e-Learning, Wuhan, Hubei, China. Her research interests include educational technology and teaching behavior analytics. 